\title{
Recent insights into xerogel and aerogel mineral composites for $\mathrm{CO}_{2}$ mineral sequestration
}

\author{
V. Morales-Flórez ${ }^{\text {a }}$, A. Santos ${ }^{\text {b }}$, L. Esquivias ${ }^{\text {a,c }}$ \\ ${ }^{a}$ Instituto de Ciencia de Materiales de Sevilla (CSIC-Universidad de Sevilla) 41092. Sevilla, Spain \\ ${ }^{\mathrm{b}}$ Departamento de Ciencias de la Tierra, Universidad de Cádiz, Puerto Real, 11510 Cádiz, Spain \\ ${ }^{c}$ Departamento de Física de la Materia Condensada, Universidad de Sevilla. 41012, Sevilla, Spain
}

\begin{abstract}
Supercritically dried composites have already been analysed and proposed as carbon dioxide sequesters. However, the economical and energetic costs of the supercritical drying process had to be re-evaluated, and were eventually found not to enhance the feasibility of the proposed route for $\mathrm{CO}_{2}$ mineral sequestration. Different composites series were synthesised with the only difference being the drying method. The structures of the porous matrix were characterised as well as their ability to capture $\mathrm{CO}_{2}$. The first results showed that the xerogel matrix is as good a host as the aerogel one, and also avoids expensive procedures such as supercritical drying for sample preparation without losing $\mathrm{CO}_{2}$ capture capacity and enhancing the efficiency of the whole carbon sequestration process. In this case, the sample preparation was simplified as much as possible, with the aim of reducing energetic and economic costs. Although good carbonation efficiencies were obtained with these cheap samples, the first results showed that previous high carbonation efficiencies could not be repeated.
\end{abstract}

\section{Keywords}

Xerogel $\cdot$ Wollastonite $\cdot$ Composite $\cdot \mathrm{CO}_{2}$ sequestration $\cdot$ Porous matrix

\section{Introduction}

Warnings about the harmful effects of climate change on the environment are stimulating the search for technologies for $\mathrm{CO}_{2}$ sequestration as an additional strategy to control the influence of anthropogenic $\mathrm{CO}_{2}$ emissions. The contribution of carbon dioxide to the greenhouse effect has been estimated to be $40-50 \%$ of the total. The main technologies currently under development or consideration are long-term storage in geological reservoirs and mineral sequestration. The mineral sequestration procedure [1] involves capturing carbon dioxide into thermodynamically stable solid carbonate minerals [2-5]. This method is similar to a natural mechanism known as rock weathering 
[6] that has regulated atmospheric $\mathrm{CO}_{2}$ over geological time. The major drawbacks of this strategy concern the efficiency of the reaction, that is, the speed of the mineral conversion into carbonate. This process typically could take decades or centuries in normal conditions and it would require the management of huge amounts of by-product. Hundreds of millions of tons of emitted $\mathrm{CO}_{2}$ would yield hundreds of millions of tons of mineral carbonates each year to dispose or eventually market. Overcoming these drawbacks is crucial to offer an economical viable technology. An attractive way to reduce costs is recycling industrial waste, for example paper mill waste [7] or portlandite waste from the acetylene industry [8].

By contrast, mineral carbonation starting from natural silicates is a slow process that must be kinetically enhanced to make this procedure useful for large-scale carbon sequestration. In aqueous systems, the divalent cation dissolution from precursor silicates seems to be the main rate-limiting step, and most research efforts have been devoted to finding ways to speed up the cation extraction from these precursor materials $[9,10]$. Most processes focus on metal oxide-bearing materials containing divalent cations, usually alkaline-earth metals or ferrous iron. Wollastonite $\left(\mathrm{CaSiO}_{3}\right)$, larnite $\left(\mathrm{Ca}_{2} \mathrm{SiO}_{4}\right)$, olivine $\left(\mathrm{Mg}_{2} \mathrm{SiO}_{4}\right)[6,11,12]$ or glauconite clays [13] incorporating iron and magnesium are usually employed for this purpose.

Some results on the rate of the conversion of wollastonite into calcite for different experimental protocols have been published $[3,14,15]$. These results must be interpreted to determine the efficiency of $\mathrm{CO}_{2}$ fixation by these minerals. Thus, starting from a powdered wollastonite sample in a reactor at atmospheric and room temperature, $14 \%$ of wollastonite converted into calcite after 22 days. A comparative study was carried out to analyse different types of samples and experimental conditions, and those obtained from powdered magnesium silicate under high pressure and temperature conditions yielded an $80 \%$ conversion after $1 \mathrm{~h}$. The critical experimental variables turned out to be sample pulverisation, the chemical species present in the aqueous solution and the high pressure and temperature conditions.

However, embedding calcium silicate grains inside a porous silica matrix was revealed as a way of enhancing carbonation efficiencies, even working in ambient pressure and temperature. That is, no extra energy supply was needed aside from solely flowing carbon dioxide through the aqueous solution of the considered powder. Thus, in the case of synthetic wollastonite powder, a $53 \%$ carbonation rate was obtained compared with an $85 \%$ rate when it was embedded in a silica aerogel matrix [Error! Bookmark not defined.]. In the case of using pure natural wollastonite powders, a $60 \%$ efficiency was obtained [11] and 100\% for embedded synthetic larnite [12Error! Bookmark not defined.]. 
The aim of this study was to improve the potentiality of the sol-gel calcium-rich composites as materials for environmental applications and to simplify and reduce the costs of those composites previously reported $[5,11,12]$. This work focuses on the analysis of the synthesis of these composites and on the structural features of the silica sol-gel porous matrix as a host of calciumrich active phases for fast carbonation reactions. The aerogel matrix was revealed as a catalyst for the carbonation reaction, but in terms of both energetic and economic efficiency, the supercritical dried composites (henceforth called aerocomposites) become unaffordable. Thus, conventional dried composites (henceforth called xerocomposites) were studied.

\section{Experimental}

Composites of raw natural wollastonite $\left(\mathrm{CaSiO}_{3}\right)$ grains embedded in a porous silica matrix were synthesised and their ability as carbon dioxide sequesters was tested. Wollastonite obtained from Aroche (Huelva, Spain) was used in the active phase for carbonation. The mineral prior to any carbonation experiment will be referred as 'original wollastonite'. Chemical analyses were made by X-ray fluorescence (XRF) (AXIOS, Panalytical with an Rh tube) using the semi-quantitative method. The mineralogical composition of this natural wollastonite was studied by X-ray diffraction (XRD) using a SIEMENS D500 powder diffraction device, starting from $10^{\circ}$ to $70^{\circ}$, collecting for $80 \mathrm{~s}$ on each step of $0.05^{\circ}$.

\subsection{Composite preparation}

Natural wollastonite was milled in an agate mortar and subsequently sieved to $<20$ microns. The powders were diluted in ethanol ( $5 \mathrm{~g}$ of wollastonite powder dispersed in $10 \mathrm{ml}$ of ethanol) with the assistance of ultrasounds. A device delivering $0.6 \mathrm{w} \cdot \mathrm{cm}^{-3}$ of ultrasound power to the system was employed. The total energy dissipated in this step was $360 \mathrm{~J} / \mathrm{cm}^{3}$. The powder obtained was added under ultrasound-assisted $\left(670 \mathrm{~J} / \mathrm{cm}^{3}\right)$ agitation to a $5 \mathrm{~mL}$ sol previously prepared by hydrolysis, and the polycondensation of tetraethoxysilane (TEOS: $\mathrm{H}_{2} \mathrm{O}: \mathrm{HNO}_{3}=1: 4: 0.026$ ) was also ultrasonically assisted with $670 \mathrm{~J} / \mathrm{cm}^{3}$ of ultrasound energy. The gels were mixed within few minutes ( $\sim 5 \mathrm{~min}$ ), which resulted in a gelling time short enough to avoid the decantation of the powders. This treatment, together with the control of gelling time, ensured the homogeneous distribution of the powder throughout the gel. To obtain the aerocomposite samples, one of the wet samples was dried under supercritical conditions of the ethanol. The xerocomposite counterparts were obtained by opening the containers to let them dry. This drying process represents a major difference in the synthesis route since no energy is used for this purpose and there is an absence of any thermal treatment after drying.

\subsection{Carbonation experiments}


In the carbonation reaction, $1 \mathrm{~mol}$ of wollastonite was converted into $1 \mathrm{~mol}$ of calcite according to the following reaction:

$$
\mathrm{CaSiO}_{3}+\mathrm{CO}_{2} \rightarrow \mathrm{CaCO}_{3}+\mathrm{SiO}_{2}
$$

The carbonation process was performed in aqueous media, at ambient pressure and temperature. The mineral sample or the composites were milled in an agate mortar and sieved at 20 microns. Altogether, $20 \mathrm{~mL}$ of a suspension of $0.01 \mathrm{~g} / \mathrm{mL}$ was subjected to steady pure $\mathrm{CO}_{2}$ bubbling of 20 $\mathrm{cm}^{3} / \mathrm{s}$ for $5 \mathrm{~min}$ at room temperature and atmospheric pressure. In some cases, some drops of $\mathrm{NaOH} 1 \mathrm{M}$ were added to keep the $\mathrm{pH}$ above 7 to favour calcite precipitation. Then, the powders were left to rest in the $\mathrm{CO}_{2}$-saturated water for $12 \mathrm{~h}$. Finally, samples were dried at $80^{\circ} \mathrm{C}$ for several hours until characterisation.

The carbonation degree of the samples was estimated by thermogravimetric analyses (TGA) using a STD Q600 experimental device. The experiments were carried out under a nitrogen flux of 100 $\mathrm{mL} / \mathrm{min}$, starting from room temperature up to $1000^{\circ} \mathrm{C}$ and rising at $10^{\circ} \mathrm{C} / \mathrm{min}$. As a reference, we have borne in mind that for a pure wollastonite sample the stoichiometric weight loss due to decarbonation is $27.5 \%$, in the range between $450^{\circ} \mathrm{C}$ and $900^{\circ} \mathrm{C}$. In real samples with impurities, the maximum weight loss has to be slightly lower. In the case of composites, the mass relative of the matrix is $\sim 30-40 \%$. In a pure sonogel, the weight lost caused by the lost of hydroxyls in the temperature interval of the calcite decarbonation is $3 \%$ [16]. Consequently, the noise introduced by the lost of residual $\mathrm{OH}$ is about $1 \%$. In the case of carbonated samples, this percentage will be even lower because the mass of added $\mathrm{CO}_{2}$ will increase the total sample mass, lowering the relative importance of the hydroxile's mass loss. The evaluation of the carbonation degree was derived from the thermogravimetric essays by measuring the mass of $\mathrm{CO}_{2}$ released between $450^{\circ} \mathrm{C}$ and $900^{\circ} \mathrm{C}$. This is the $\mathrm{CO}_{2}$ captured in the calcium-rich active phase as calcite, and it can be compared with the maximum $\mathrm{CO}_{2}$ that would be possible to capture stoichiometrically. To obtain the theoretical maximum of possibly captured carbon dioxide, the weight percentage of the active phase in the composite and the purity of the mineral phase evaluated by XRF were considered. Then, the carbonation degree was obtained as the ratio between the actual mass loss due to the release of $\mathrm{CO}_{2}$ and the theoretical maximum. To compare the experimental results with this theoretical maximum, the outputs of the TGA experiments were normalised to the weight of the dehydrated sample, that is, the weight at $\mathrm{T}=200^{\circ} \mathrm{C}$, once all the adsorbed water had been completely removed.

\subsection{Characterisation of the composites}


Once the composites had gelled and dried, their morphology was characterised by combining nitrogen physisorption experiments and scanning electron microscopy (SEM). Physisorption experiments were completed in a Micromeritics device model ASAP2010, at a constant temperature of $77.35 \mathrm{~K}$. Samples were milled and degasified at $150^{\circ} \mathrm{C}$ under a vacuum for $2 \mathrm{~h}$ prior to the experiment. The specific surface area and pore size distribution were obtained by analysing the physisorption isotherm using the BET [17] and BJH [18] methods, respectively. The specific surface area of the mineral crystals in the carbonated samples was neglected, and measured $S_{B E T}$ values were assigned to the porous matrix contribution of the composite. SEM was performed in a SEMFEG Hitachi S480 using an acceleration voltage of $2 \mathrm{kV}$. The aerocomposite was also analysed by transmission electron microscopy (TEM), and the chemical nature was revealed with a coupled EDX analysis (Link-ISIS device).

\section{Results and Discussion}

\subsection{Porous matrix}

The structural role of the silica matrix was studied as the host of active phases for carbonation. In this regard, structural analysis was performed to resolve the processes involved in the carbonation reaction under these conditions. In the case of the xerocomposite Xero40, the analysis of the structure of the silica gel matrix host by nitrogen physisorption gave a specific surface area of 49 $\mathrm{m}^{2} / \mathrm{g}$. The label " 40 " corresponds to the $\mathrm{CaO}$ content if we were working with pure wollastonite. This mineral content was chosen as the maximum amount of powder that could be embedded into a silica gel. This was tested by introducing different amounts of powder into the sol, and the samples that gelled with the maximum $\mathrm{CaO}$ content were those with the nominal $40 \mathrm{wt} . \% \mathrm{CaO}$ content. The samples with greater $\mathrm{CaO}$ content did not gel and two different phases, the mineral grains and the silica sol, could always be observed.

Although the embedded wollastonite was finely milled, the contribution of the specific surface area was negligible. Then, because the $80 \mathrm{wt} . \%$ of the total mass of the sample is approximately mineral grains, it can be deduced that the specific surface due only to the host matrix is around $250 \mathrm{~m}^{2} / \mathrm{g}$. Considering the sample Xero26, (that is, with a $\mathrm{CaO}$ nominal content of $26 \mathrm{wt} . \%$ ), the specific surface area obtained was $153 \mathrm{~m}^{2} / \mathrm{g}$. Again, this nanostructure can be associated to the silica gel matrix that represents approximately half of the total weight. Consequently, the specific surface area of the matrix can be $300 \mathrm{~m}^{2} / \mathrm{g}$. These specific surface area values are significantly lower than those from the aerogel composites previously reported [11]. The texture parameters are summarised in Table 1. The mean pore size in both silica matrices of the Xero26 and Xero40 samples were very similar, with both close to $3.5 \mathrm{~nm}$. Accordingly, we can appreciate that similar matrices were synthesised regardless of the amount of embedded mineral grains. 
Next, the role of the hosting matrix was analysed on the basis of the SEM images. Figure 1 clearly shows two wollastonite grains with sizes below 3 microns, completely covered by a porous layer of silica gel. This porous layer constitutes the phase that avoids the mineral grains to get matted and, in the case of pure wollastonite [11], to allow large carbonation degrees without the formation of passivating layers. Actually, in Figure 1 the same porous matrix, showing that the matrix covers large areas of the sample, forms all the observed surfaces. However, not all the grains are completely covered by the porous silica.

In Figure 2 (top), one grain of the raw mineral is partially covered by large pieces of silica gel. A sort of broken coating can be discerned over the surface of the mineral grain. This xerogel coating will avoid the aggregation of the grains when in solution and during bubbling, but it will not ultimately avoid the precipitation of a calcite passivating layer over large areas of the surface of the mineral. In Figure 2 (bottom), a detailed image of the coating is shown. With the help of the ImageJ free software $\left[{ }^{19}\right]$, the image was analysed and the thickness of the coating could be resolved. It was found that the average layer thickness was $600 \pm 100 \mathrm{~nm}$. Thus, these xerocomposites present an active phase formed by mineral grains smaller than 20 microns that are covered by a $600 \mathrm{~nm}$ silica porous coating.

The matrix's role is avoiding the passivating layer formation as can be seen in Figure 3 (highlighted by the arrow). The new precipitated calcite layer can be observed covering the silica gel coating. Therefore, the calcite resulting from the carbonation attack is precipitated over the outer face of the grain coating. This fact has a major relevance because the gel coating of the mineral grains will continue, thereby allowing the water to diffuse through the matrix despite the precipitation of the $\mathrm{CaCO}_{3}$. That is, it will be possible to keep on dissolving the ions of the mineral and diffusing the carbonic ions. Therefore, the carbonation process goes beyond the initial passivating layer.

However, the images of the aerocomposites revealed a highly homogeneous distribution of the matrix. The mineral grains are usually hidden in the matrix (Figure 7, left) and it was difficult to find some mineral grains easy to resolve after several tens of images and two SEM sessions. In fact, TEM and chemical analyses (Figure 7, centre and right, respectively) were performed on the samples to ensure that calcium-rich phases were embedded into the matrix. This way, it was confirmed that wollastonite was actually homogeneously embedded into the porous matrix. Therefore, previously reported carbonation results confirmed that carbon dioxide and water diffuse through the porous matrix and no passivating effect can be found in these aerocomposites. Coating obtained by supercritical drying is more homogeneous than that by conventional drying. This permits us to suppose that the carbonation efficiency of aerocomposites is higher than that of their xero counterparts. 


\subsection{Carbonation}

XRF chemical analysis of the natural wollastonite revealed a low $\mathrm{CaO}$ content of $17.7 \mathrm{wt} . \%$ and a $\mathrm{SiO}_{2}$ content of $59.9 \mathrm{wt}$ \%. Moreover, $\mathrm{Al}_{2} \mathrm{O}_{3}$ and $\mathrm{Fe}_{2} \mathrm{O}_{3}$ content is also important. The detailed chemical composition is shown in Table 2. Thus, in the case that all the $\mathrm{CaO}$ corresponding to wollastonite, the purity of these natural wollastonite samples would be slightly higher than $36 \%$, being the other major component pure $\mathrm{SiO}_{2}$. Therefore, the maximum stoichiometric weight loss of a completely carbonated sample of this raw wollastonite in a TGA would be $12 \%$. This value will be considered as a reference, but it is significantly lower than our former analysis of these rocks from Aroche [11]. Consequently, a large dispersion on the mean calcium content should be expected. This fact will be crucial in the estimation of the efficiency of the mineral sequestration with raw wollastonite, and might turn out to be a major drawback for scaling up the process.

The mineralogical composition of the sample prior to the $\mathrm{CO}_{2}$ attack was calculated from the chemical composition abridged in Table 2. In Figure 1, the XRD pattern is shown and the major phases are identified. Cristobalite $\left(\mathrm{SiO}_{2}\right.$; PDF card: 00-039-1425), wollastonite-2M ( $\mathrm{CaSiO}_{3} ; \mathrm{PDF}$ card: 00-027-0088) and $\alpha$-quartz ( $\mathrm{SiO}_{2}$; PDF card: 01-078-1253) were mainly found. In addition, some calcite ( $\mathrm{CaCO}_{3}$; PDF card: 00-005-0586), hedenbergite ( $\mathrm{CaFeO}_{6} \mathrm{Si}_{2}$; PDF card: 00-024-0205) and microperthite ( $\mathrm{AlK}_{0.96} \mathrm{Na}_{0.04} \mathrm{O}_{8} \mathrm{Si}_{3}$; PDF card: 01-083-1895) were identified. Therefore, the presence of small amounts of calcium carbonate prior to the $\mathrm{CO}_{2}$ attacks has to be considered to accurately ascertain the degree of carbonation. This offset of the carbonation degree was estimated by thermogravimetry (Figure 2). The weight loss of around $600-700^{\circ} \mathrm{C}$ of the original wollastonite can be explained in terms of the release of the $\mathrm{CO}_{2}$ from the calcite. That is, $21 \%$ of the $\mathrm{CaO}$ content of the original sample comes from calcite or, in terms of the degree of carbonation, it can be stated that before carbonation experiments the sample was $21 \%$.

The effect of the carbonation attacks was also verified in the TGA. Firstly, the carbonation of the milled wollastonite was studied, with and without of $\mathrm{pH}$ control with $\mathrm{NaOH}$. In Figure 2, the different results are plotted and the carbonation degrees of each system are listed in Table 3. Bubbling carbon dioxide allows the slight increase of the carbonation degree up to $32 \%$. In this case, $\mathrm{pH}$ went down to 6 . However, if the $\mathrm{pH}$ is held above 7 , the carbonation degree reached $52 \%$. This simple test confirms that the control of the $\mathrm{pH}$ is crucial for obtaining large carbonation degrees, as expected. But the goal of this technology is to raise this carbonation degree close to $100 \%$ with the help of a host porous matrix, as obtained in previous works with composites.

Secondly, the xerocomposites labelled Xero40 were analysed and their carbonation degrees were estimated by TGA. Three different samples were analysed by thermogravimetry: the Xero40 before the $\mathrm{CO}_{2}$ attack and carbonated xerocomposites with and without $\mathrm{pH}$ control. The original 
xerocomposite weight lost was $1.5 \%$ corresponding to $17 \%$ of the degrees of carbonation, near to that of raw wollastonite $(21 \%)$, as expected. However, the carbonated samples presented low degrees of carbonation. In total, $24 \%$ of the carbonation degree was obtained without $\mathrm{pH}$ control and $51 \%$ with. The behaviour is exactly the same as obtained with milled mineral, that is, without the host silica matrix. If no $\mathrm{pH}$ control was used, when starting the gas bubbling, the $\mathrm{pH}$ drops close to 5 , from an initial value of 8.5. This low $\mathrm{pH}$ value allowed us to foresee that carbonation degree would not be very high. Under these conditions, the concentration of $\mathrm{CO}_{3}{ }^{2-}$ and $\mathrm{CO}_{3} \mathrm{H}^{-}$anions drop drastically when the $\mathrm{pH}$ drops below 6 .

Accordingly, under these experimental conditions, no extra carbonation is obtained as a consequence of using a porous matrix hosting the mineral grains, contrary to those results reported before for pure wollastonite [5,11]. Thinking in terms of the environmental applications of this technology, $\mathrm{pH}$ buffers will be necessary, as soda-bearing industrial wastes.

One major explanation to the differences obtained in this work regarding our previous results can be attributed to the active phase impurities. In this regard, chemical and mineralogical analyses indicated less than $36 \%$ of wollastonite content in the natural sample, whereas XRD in the previous work revealed the presence of wollastonite-1T only. Given that the divalent cation dissolution from the precursor silicates seems to be the main rate-limiting step, the presence of large silica-rich phases can avoid the $\mathrm{Ca}^{2+}$ dissolution simply by steric effects. In addition, the other silicates inhibit the dissolution of the $\mathrm{Ca}^{2+}$ cation from wollastonite, reducing in this way the carbonation rate. The xerogel matrix where the mineral is embedded avoids the formation of the passivating layer [Error! Bookmark not defined.] but could not enhance the dissolution of the cations. Even though both samples came from the same source (Aroche, Spain), impurities seem to be a disperse parameter and crucial for the carbonation reaction to take place. In this case, it is not the formation of a passivating layer that hinders the carbonation reaction but the presence of an enormous quantity of impurities.

Finally, the incomplete recovery of the grains will not impede the precipitation of a calcite passivating layer over large areas of the surface of the mineral. Consequently, this explains the reasons why the xerocomposite presents worse carbonation efficiencies than expected. Taking this into account, it will be necessary to look for routes of synthesising silica gel matrices that do not collapse during solvent evaporation [20] without consuming too much energy.

\section{Conclusions}


1. The synthesis of calcium-rich composites for environmental applications has been simplified using natural raw wollastonite as the active phase and standard drying in air. No heat treatment was used in the final stage of the synthesis, lowering even more the global energy consumption. However, the use of $\mathrm{NaOH}$ to control the $\mathrm{pH}$ was crucial for speeding up the calcium carbonate precipitation.

2. With a very small $\mathrm{CO}_{2}$ attack and under ambient pressure and temperature, $50 \%$ carbonation was achieved. However, embedding the active phase in a silica porous matrix did not enhance the carbonation. The impurities, which act as a sort of passivating layer, screen the catalytic effect of the hosting pores. In this context, it is advisable to search for purer calcium silicate as the active phase, although this might become necessary considering industrial wastes as precursors to reduce the costs.

3. It was confirmed that the silica gel matrix conventionally dried allows the carbonation of the mineral grains and the precipitation of the carbonate over the matrix. However, some grain areas appear uncoated, where some passivating carbonate layer could eventually precipitate.

4. Higher carbonation efficiencies in the aerocomposites should be expected because no passivating effects have ever appeared, in agreement with the homogenous and continuous coating observed.

\section{Acknowledgements}

The authors would like to acknowledge José Manuel Cantó Romera for supplying the raw wollastonite mineral directly from the mines of Aroche (Spain) and his brave fight against the environmental threat. In addition, L.M. Pérez is also recognised for his help on the synthesis of the samples. The authors are also grateful to the Consejería de Innovación Ciencia y Empresa of the Junta de Andalucía (Spain) for supporting this work with the annual grant TEP115 and to the Ministerio de Ciencia e Innovación of the Spanish Government for grant PIA42008-31. This work was possible thanks to the technical staff of the Instituto de Ciencia de Materiales de Sevilla (CSICUS). V. Morales-Flórez also thanks the JAE program of the Consejo Superior de Investigaciones Científicas (CSIC) for its financial support. 
Tables and figures

Captions

Table 1. Texture parameters of the synthesised xerocomposites. The labels " 49 and " 26 " correspond to the $\mathrm{CaO}$ content embedded if we were working with pure wollastonite.

Table 2. Chemical composition of the mineral wollastonite obtained by X-Ray fluorescente.

Table 3. Carbonation efficiencies of the samples. *Actual weight loss/maximum theoretical weight loss..

Figure 1: XRD pattern of the original mineral wollastonite. Identified phases are cristobalite (PDF card: 00-039-1425), wollastonite-2M (PDF card: 00-027-0088), quartz- $\alpha$ (PDF card: 01-078-1253), calcite (PDF card: 00-005-0586), hedenbergite (PDF card: 00-024-0205) and microperthite (PDF card: 01-083-1895).

Figure 2: Thermogravimetric analysis of the carbonated natural wollastonite and the xerocomposite Xero40.

Figure 3: SEM image of the wollastonite grains embedded in the silica gel matrix.

Figure 4. Top: SEM image of the broken coating of the mineral grains. Silica gel matrix does not completely cover the grains. Bottom: Detailed SEM image of the silica gel covering the mineral grain. Thickness of the coating can be estimated to be around $600 \mathrm{~nm}$.

Figure 5. Pointed by the white arrow, carbonation layer precipitated over the silica gel coating of the grains.

Figure 6. SEM image of the aerocomposite. The supercritically dried coating covers homogeneously the mineral grains.

Figure 7: From left to right: SEM, TEM and coupled chemical analysis of the aerocomposite. The lighter areas of the grain in the chemical analyses (green on the coloured version) correspond to calcium-rich areas. 


\section{References}

1. Seifritz W (1990) Nature 345:486.

2. Bearat H, McKelvy MJ, Chizmeshya AVG, Sharma R, Carpenter RW (2002) J Am Ceram Soc 85:742-748

3. Zevenhoven R, Eloneva S, Teir S (2006) Catal Today 115: 73-79

4. Lackner KS (2003) Science 300:1677-1678

5. Santos A, Toledo-Fernández JA, Mendoza-Serna R, Gago-Duport L, de la Rosa-Fox N, Piñero M, Esquivias L (2007) Ind Eng Chem Res 46:103-107

6. Kojima T, Nagamine A, Ueno N, Uemiy S (1997) Energy Convers Manage 38(1):S461-S466

7. Pérez-López R, Montes-Hernandez G, Nieto JM, Renard F, Charlet L (2008) Applied Geochemistry 23:2292-2300

8. Esquivias L, Santos A, Morales-Flórez V (2009) "Eliminación del dióxido de carbono y otros gases atmosféricos mediante residuos industriales ricos en calcio" Spanish Patent P201000062

9. Wolf GH, Chizmeshya AVG, Diefenbacher J, McKelvy MJ (2004) Environ Sci Technol 38:932936

10. Kakizawa M, Yamasaki A, Yanagisawa Y (2001) Energy 26:341-354

11. Santos A, Ajbary M, Kherbeche A, Piñero M, de la Rosa-Fox N, Esquivias L (2008) J Sol-Gel Sci Technol 45:291-297

12. Santos A, Ajbary M, Morales-Flórez V, Kherbeche A, Piñero M, Esquivias L (2009) Journal of Hazardous Materials 168(2-3):1397-1403

13. Fernandez-Bastero S, Garcia T, Santos A, Gago-Duport L (2005) Ciencias Marinas 31:593-615

4. Wu JCS, Sheen JD, Chen SY, Fan YCh (2001) Ind Eng Chem Res 40:3902-3905

5. Tai CY, Chen WR, Shih SM (2006) AIChE J 52:292-299

16 Esquivias L and Zarzycki J (1986). In: Baró MD and Clavaguera N (eds) Current Topics on Non Crystalline Solids, World Scientific, Singapore pp. 409-4164.

17. Brunauer S, Emmett PH, Teller E (1938) J Am Chem Soc 60:309-319

18. Barret EP, Joyner LG, Halenda PP (1951) J Am Chem Soc 73:373-380

19. ImageJ 1.42q, Rasband W, Nacional Institutes of Health (USA).http://rsb.info.nih.gov/ij. Last visit: March, 2010.

20. Laberti-Robert C, Long JW, Lucas EM, Pettigrew KA, Stroud RM, Doescher MS, Rolison DR (2006) Chem Mater 18:50-58 
Click here to download high resolution image
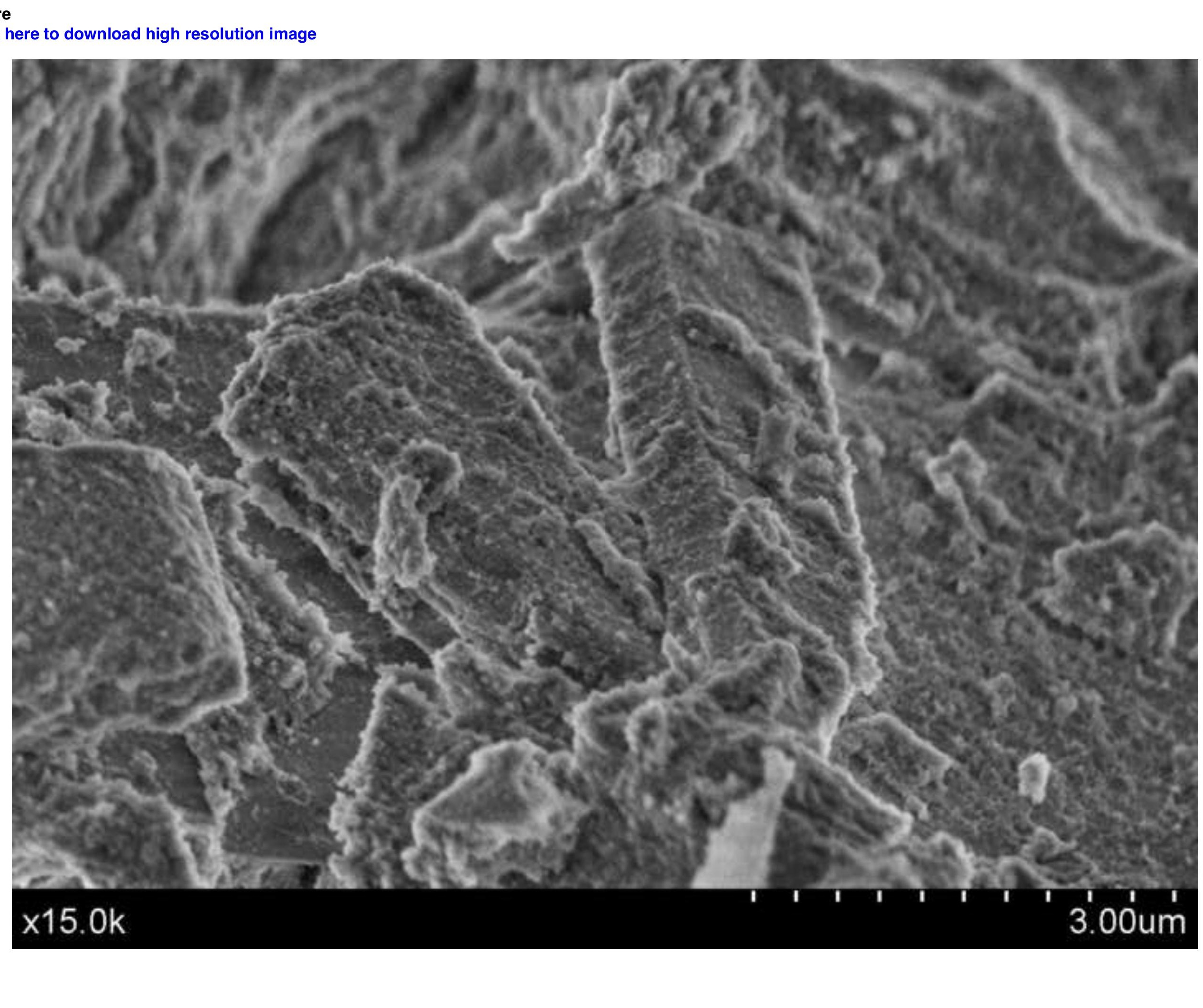


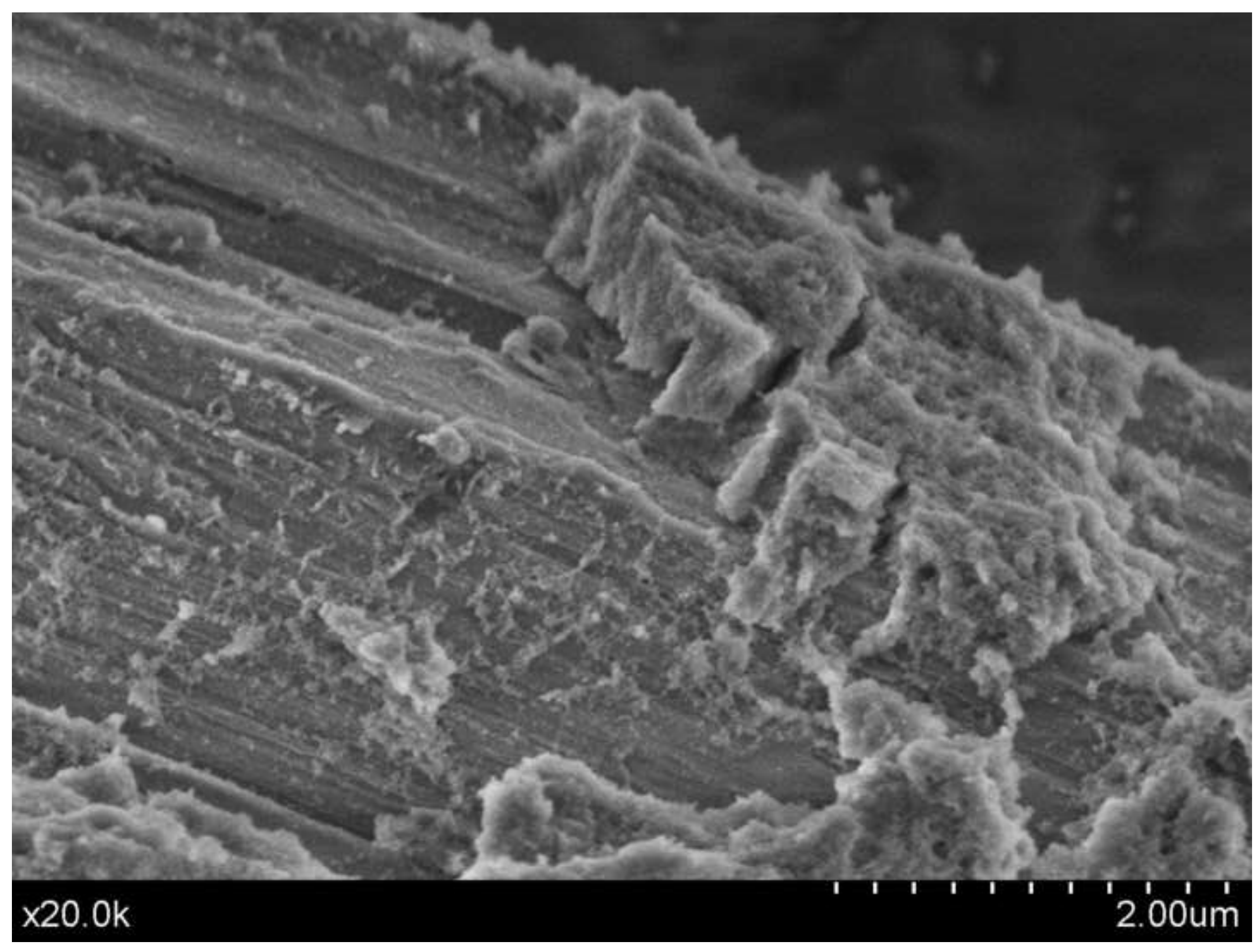

\section{Click here to download high resolution image}

$20.0 \mathrm{~K}$
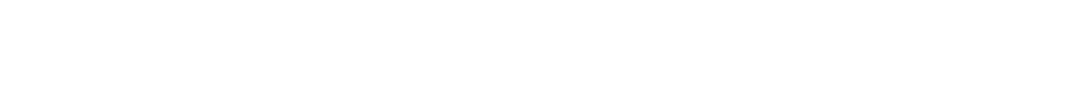


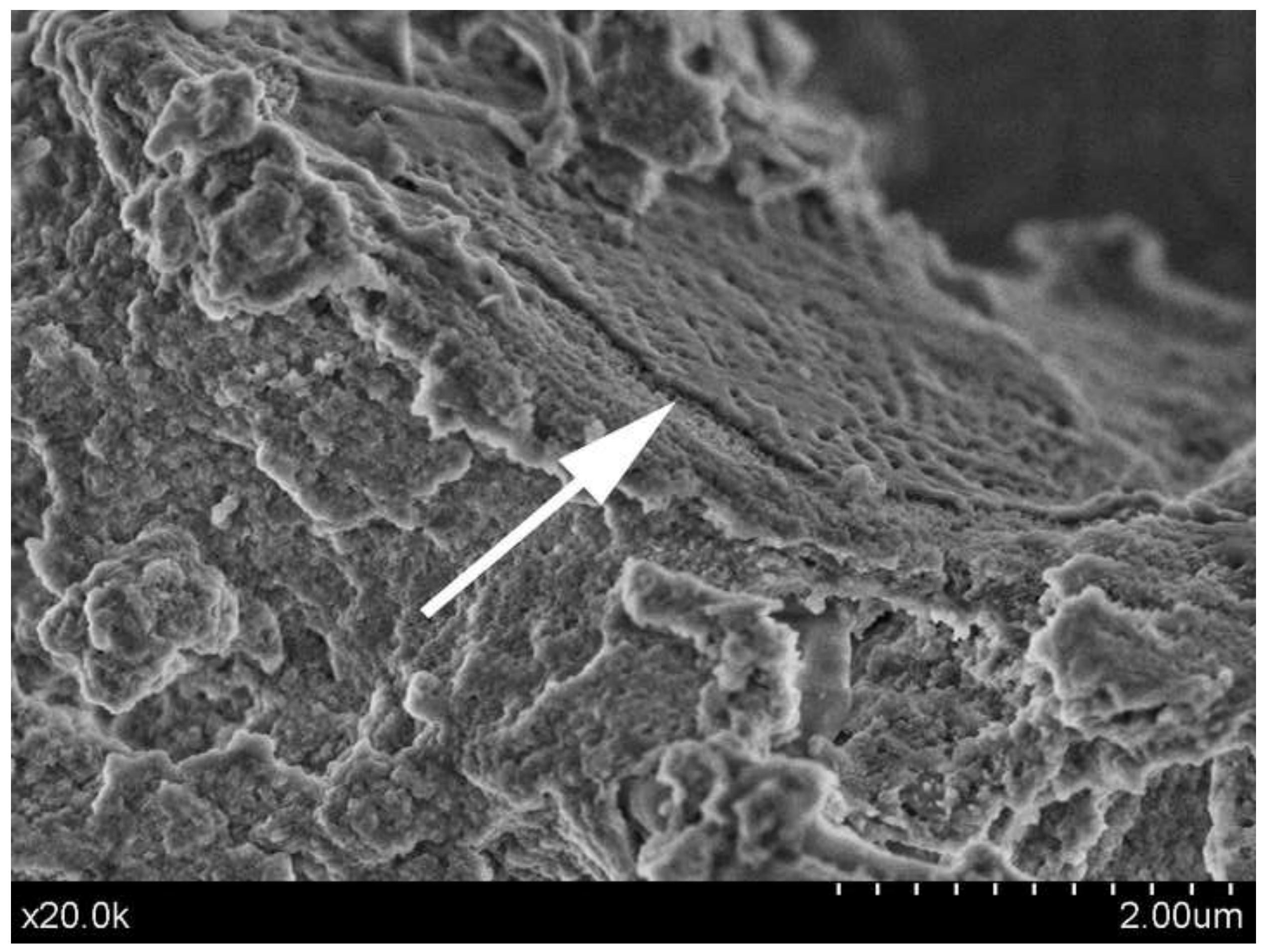

\section{Figure
Click here to download high resolution image}

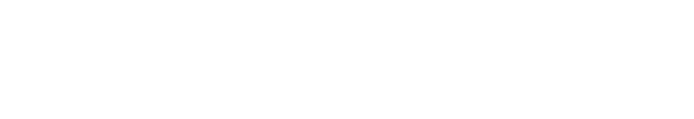


Click here to download high resolution image

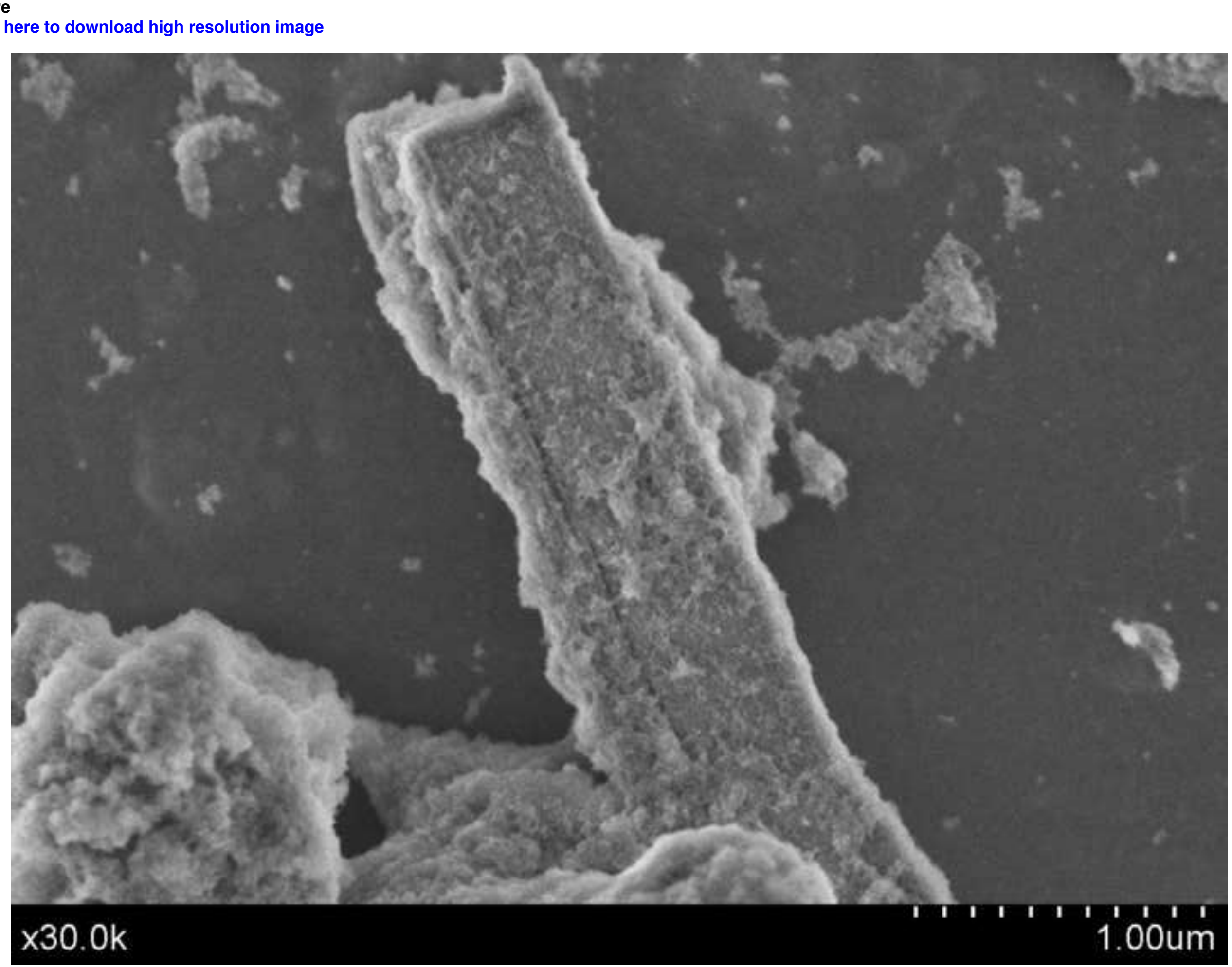

$\times 30.0 \mathrm{k}$
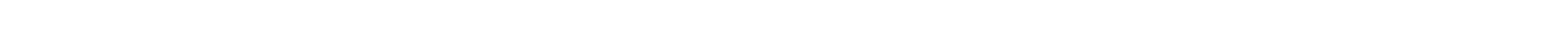


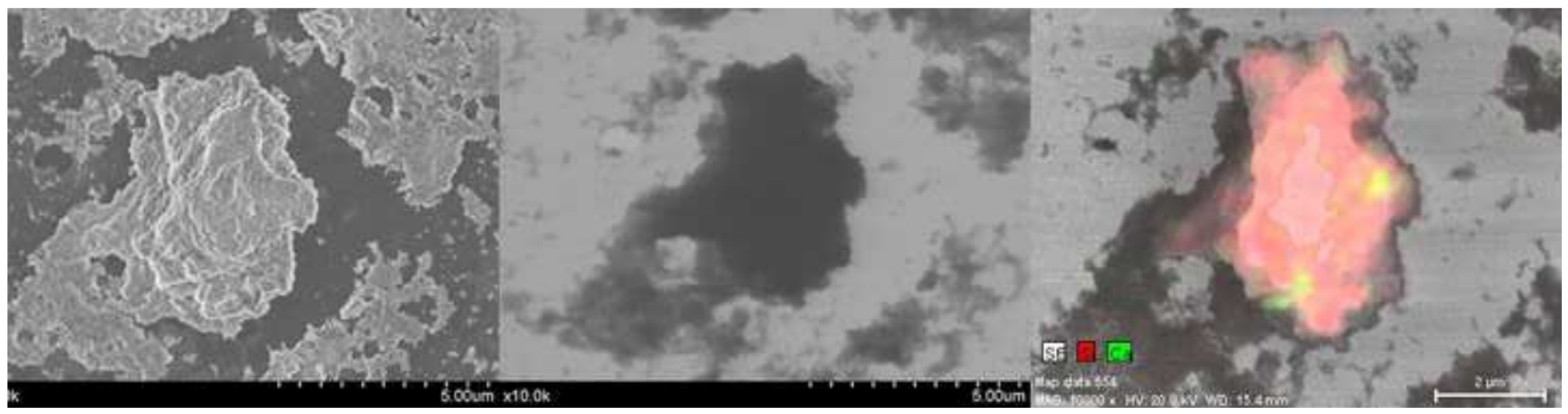




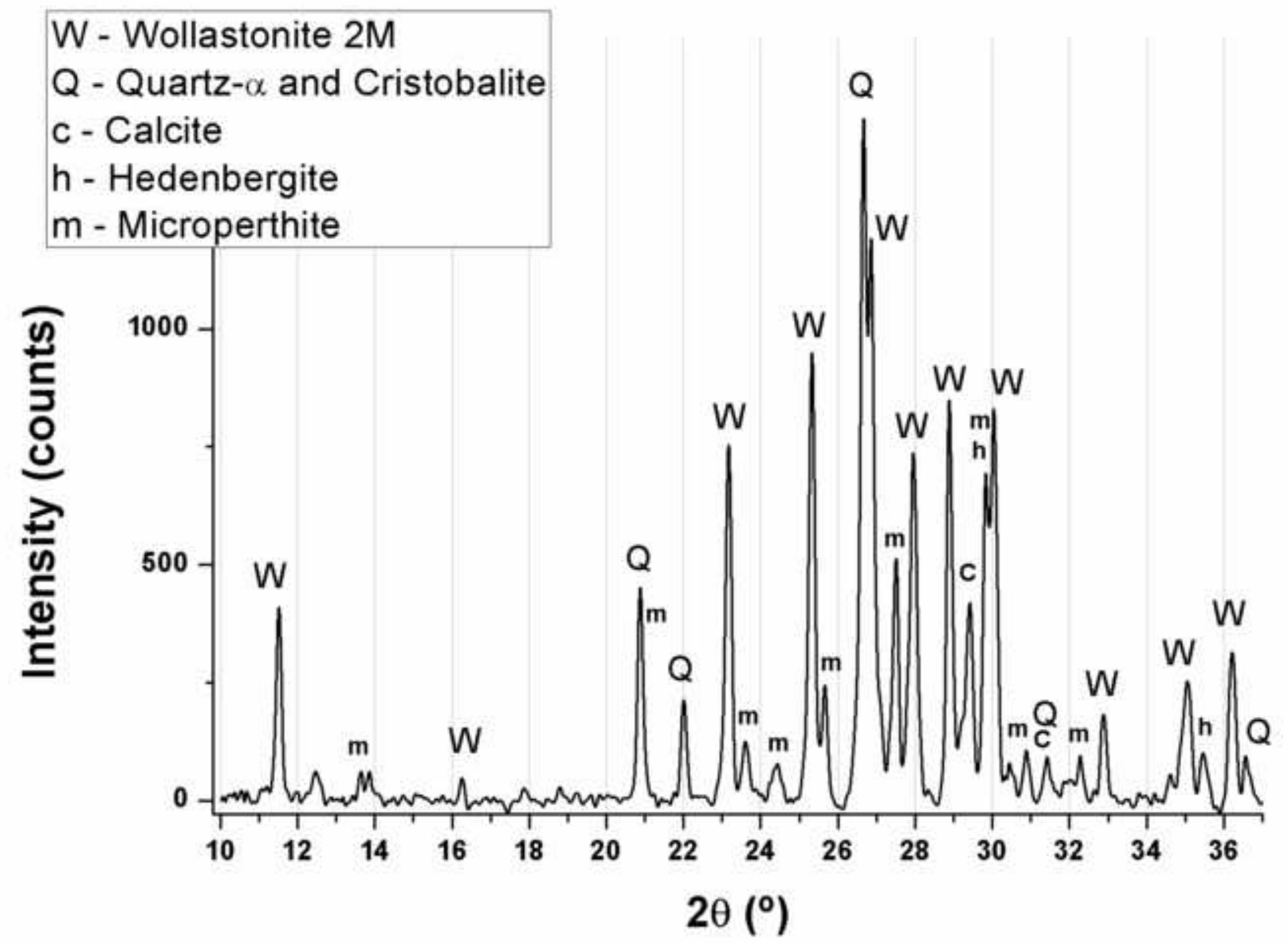




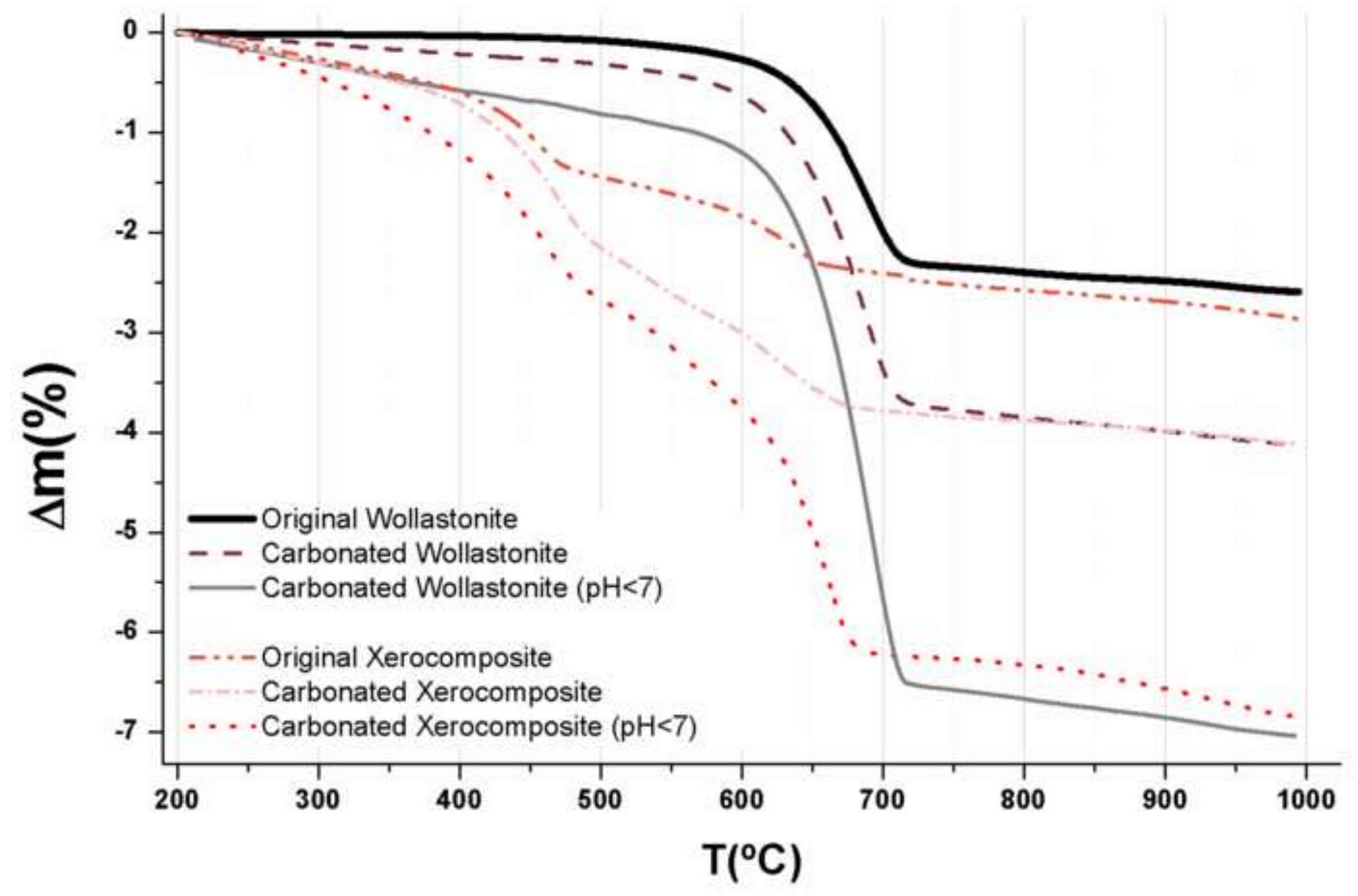


Table

Click here to download Table: Table 1.doc

Tables

Table 1

Texture values

\begin{tabular}{cccc}
\hline Sample & $\begin{array}{c}\text { Specific surface area } \\
(\mathrm{m} 2 / \mathrm{g})\end{array}$ & $\begin{array}{c}\text { Mean Pore size } \\
(\mathrm{nm})\end{array}$ & $\begin{array}{c}\text { Porous } \\
\text { volume } \\
(\mathrm{cm} 3 / \mathrm{g})\end{array}$ \\
\hline Xero26 & 153 & 3.5 & 0.169 \\
\hline Xero40 & 49 & 3.7 & 0.074 \\
\hline
\end{tabular}


Click here to download Table: Table 2.doc

Table 2

\begin{tabular}{ccccccccc}
\hline & $\mathrm{SiO}_{2}$ & $\mathbf{C a O}$ & $\mathrm{Al}_{2} \mathrm{O}_{3}$ & $\mathrm{Fe}_{2} \mathrm{O}_{3}$ & $\mathrm{Na}_{2} \mathrm{O}$ & $\mathbf{M g O}$ & $\mathbf{K}_{2} \mathrm{O}$ & \\
\hline $\begin{array}{c}\text { Natural Wollastonite } \\
\text { chemical } \\
\text { composition } \\
\text { (wt. \%) }\end{array}$ & 59,9 & 17,7 & 10,7 & 5,3 & 2,0 & 1,6 & 1,1 & $\begin{array}{c}\text { Traces of } \mathrm{TiO}_{2}, \\
\mathrm{P}_{5}, \mathrm{SrO}_{2}, \mathrm{SO}_{3} \\
\text { and } \mathrm{MnO}(<1 \%)\end{array}$ \\
\hline
\end{tabular}


Click here to download Table: Table 3.doc

Table 3

Carbonation efficiency

\begin{tabular}{|c|c|}
\hline Sample & AWL/MTWL* \\
\hline Original Wollastonite & $21 \%$ \\
\hline Carbonated Natural Wollastonite & $32 \%$ \\
\hline $\begin{array}{r}\text { Carbonated Natural Wollastonite } \\
(\mathrm{pH}<7)\end{array}$ & $52 \%$ \\
\hline $\begin{array}{ll}\text { Original Xero40 } \\
\end{array}$ & $17 \%$ \\
\hline Carbonated Xero40 & $24 \%$ \\
\hline $\begin{array}{r}\text { Carbonated Xero40 } \\
(\mathrm{pH}<7)\end{array}$ & $51 \%$ \\
\hline
\end{tabular}

